Running head: Attitudes to sexual offenders

\title{
Development of a 21-item short form of the Attitudes to Sexual Offenders (ATS) scale
}

\author{
Todd E. Hogue* \\ University of Lincoln (UK) \\ Craig A. Harper \\ Nottingham Trent University (UK)
}

Author Note

Todd E. Hogue, Professor of Forensic Psychology, School of Psychology, University of Lincoln, UK

Craig A. Harper, Lecturer in Human Psychology, Department of Psychology, Nottingham Trent University, UK;

*Correspondence concerning this article should be addressed to Prof. Todd Hogue, School of Psychology, University of Lincoln, Brayford Pool, Lincoln LN6 7TS.

E-mail: thogue@lincoln.ac.uk

\section{Acknowledgements}

The authors wish to extend thanks to Genevieve Ranger, Rebecca Wilson, and Gemma Stirland for their role in data collection for this project. 


\begin{abstract}
The Attitudes to Sexual Offenders scale (ATS; Hogue, 1993) is one of the most widely-used measurement instruments for assessing views about sexual offenders. The ATS has been used in a variety of contexts, most commonly in comparing forensic professionals and non-professionals in relation to their views about this population. This paper offers a review of the methods used to examine attitudes toward sexual offenders currently available, before systematically outlining the validation of a 21 -item shortened version of the ATS measure (the 'ATS-21'). First, we analyzed the ATS with regards to its underlying factor structure using a general community sample (Study $1 ; n=188$ ). This identified three factors: 'Trust', 'Intent', and 'Social Distance'. We subsequently supported this structure through confirmatory factor analysis in a new community sample (Study $2 ; n=335$ ) and Hogue's (1993) original ATS development data (Study $3 ; n=170$ ) in order to provide further evidence of its reliability. We also offer preliminary evidence of the ATS-21's test-retest reliability, consistency across multiple testing contexts, resistance to social desirability, and independence from related measures (Study $4 ; n=59$ ). We close by recommending the use of the ATS-21 for researchers examining attitudes toward sexual offenders and offer suggestions for a new unified research design to incorporate the ATS-21 into emerging research into the psychological underpinnings of attitudes and responses to sexual offenders. We offer open data at https://osf.io/ymhsw/ and open scoring resources for the ATS-21 at https://osf.io/34hsx/.
\end{abstract}

Keywords: attitudes; sexual offenders; scale validation; factor analysis; clinical judgements

\title{
Public Significance
}

The present study demonstrates that attitudes toward sex offenders can be effectively measured by the revised 21 item Attitudes toward Sex Offenders Scale. Such attitudes should be considered more consistently as they have the potential to influence professional judgements, treatment effectiveness, and policy decisions at the political level. 


\section{Development of a 21-item short form of the Attitudes to Sexual Offenders (ATS) scale}

Attitudes toward sexual offenders are popular and important topics for empirical inquiry in the study of social views about the criminal justice system. The potential implications of attitudinal orientations about sexual offenders are profound, particularly in relations to social, political, and clinical decision-making (Harper, Hogue, \& Bartels, 2017; Willis, Levenson, \& Ward, 2010). For example, attitudes toward this group of offenders play an important role in the guiding of specific legislative changes in relation to their management (Harper \& Hogue, 2014), impact upon prison-based therapeutic climates in treatment settings (Blagden, Winder, \& Hames, 2016), guide responsibility judgements in rape cases (Hogue \& Peebles, 1997), and effects public willingness to volunteer with offenders to facilitate reintegration (Lowe, Willis, \& Gibson, 2017; Richards \& McCartan, 2018). As such, the development and validation of a reliable measurement of such attitudes is an important empirical exercise.

In this paper, we present a revalidation of the Attitudes to Sexual Offenders (ATS) scale (Hogue, 1993) using several community and professionally-based samples. First, the ATS is investigated using principal components analysis (Study $1 ; n=188$ ) and confirmatory factor analyses (Study $2 ; n=335$ ), identifying the underlying factor structure of a short form of the ATS. Following this, we examine the reliability of the revised ATS in relation to data collected in the scale's initial development study (Study $3 ; n=170$ ). We then present evidence of the revised ATS measure's stability over different forms of completion (Study 4; $n=59)$.

The overarching goal and contribution of this paper is to highlight the methodological issues that currently exist in ATS research, and to provide the field with a revised, reliable, and theoretically valid measure of attitudes toward sexual offenders. We go on to outline a holistic approach to ATS research that can unify the field around a single research paradigm, 
such as to effectively, efficiently, and uniformly assess attitudes toward sexual offenders and their impact on social and professional behavior.

\section{Differentiating 'Attitudes' and 'Perceptions' about Sexual Offenders}

When discussing psychological constructs, it is important to first operationalize the topic under investigation. When we discuss 'attitudes', we refer to a tripartite approach to evaluation, such as the ABC model advocated by Breckler (1984). This model asserts that there are three components to 'attitudes' (irrespective of the target of such views).

First, there is an affective component (A). This refers to the automatic emotional responses that we have to the target attitude object. In relation to sexual offenders, several authors have argued that the phrase 'sexual offender' evokes visceral responses such as disgust, fear, and loathing (e.g., Bastian, Denson, \& Haslam, 2013; Vess, 2009), and that these emotional responses can give rise to more punitive responses than when more sanitized or descriptive labels are used (Harris \& Socia, 2016).

Second, attitudes are argued to possess a behavioral component (B). This aspect of attitudes is related to how one interacts with a target attitude object in the social world. In relation to sexual offenders, Brown (1999) described how people may be generally supportive of community-based sexual offender treatment as an attempt to reduce recidivism, so long as this treatment does not take place in their community. This 'not-in-my-backyard' (NIMBY) approach to sexual offender policy is a commonly-reported phenomenon (e.g., Cook \& Hogue, 2013), and is driven by a desire for social distance from a demonized and stigmatized 'sexual offender outgroup' (Harper et al., 2017).

Finally, attitudes have a cognitive component (C). This refers to the stereotypes and attributions that are held about a particular attitude object. In relation to sexual offenders, these views typically consist of the opinion that people with convictions for sexual offences 
are mentally ill, sexually deviant, and resistant to treatment (and thus, are unlikely to change (e.g., Galeste, Fradella, \& Vogel, 2012; Sanghara \& Wilson, 2006).

Clearly, there is some level of overlap between these three components of attitudes. For example, those with a more negative automatic emotional response to sexual offenders, when coupled with the stereotype that this population is resistant to change, are likely to support punitive and controlling social policies in relation to the management of sexual offenders. However, the point here is that attitudes are comprised of different facets that are (at best) implicit or (at worst) ignored in current ATS research, which typically conceptualizes attitudes toward sexual offenders in a manner that suggests they are unidimensional.

\section{Current Approaches to Measuring Attitudes to Sexual Offenders}

At present, the literature around attitudes toward sexual offenders predominantly makes use of explicit (self-report) measurement procedures, with studies typically using one of two key scales: (1) the Attitudes to Sexual Offenders (ATS) scale (Hogue, 1993), and (2) the Community Attitudes toward Sex Offenders (CATSO) scale (Church, Wakeman, Miller, Clements, \& Sun, 2008).

The ATS scale. The ATS (Hogue, 1993) is a 36-item self-report measure, which was adapted from the Attitudes to Prisoners (ATP) scale (Melvin, Gramling \& Gardner, 1985) by replacing the descriptor used in the ATP from "prisoner(s)" to "sex offender(s)". The items on the ATS are framed as broad attitudinal statements (e.g., "Sex offenders are no better or worse than other people"). Against these statements, respondents are asked to rate their level of agreement using a five-point Likert scale, ranging from 1 ('Strongly Disagree') to 5 ('Strongly Agree'). 19 of the items are reverse-scored, and a constant of 36 (one for each item) is subtracted from the total score. Functionally, this means that each ATS item is scored 
on a scale of 0-4, leaving a potential scoring range of 0-144. Higher scores on the ATS are indicative of more positive attitudes toward sexual offenders. The ATS measure has demonstrated excellent internally consistent in a number of different studies $(\alpha>0.80$; Craig, 2005; Harper \& Hogue, 2015; Harper \& Bartels, 2018; Higgins \& Ireland, 2009; Kjelsberg \& Loos, 2008; Kleban \& Jeglic, 2012; Proeve \& Howells, 2006).

The ATS was designed as a measure of global (unidimensional) attitudes toward sexual offenders, with Hogue (1993) not undertaking any additional validation of the ATS when developing the scale. In this regard, the measure should be viewed as a reflection of generalized feelings about this offender population, and thus we conceptualize it as a baseline measure of attitudes. However, many authors have not used the ATS in this way. For example, Gakhal and Brown (2011), for example, adapted the items of the ATS to be applicable to "female sex offender(s)". Similarly, Harper (2012) substituted the reference group "sex offender(s)" for the names of sexual offenders that he presented in a series of experimental vignettes investigating views of juvenile sexual offenders. Using the ATS in ways such as these is to conceptualize the scale as an outcome measure (see also Kleban \& Jeglic, 2012), and is inconsistent with the intended use of the ATS as suggested by Hogue (1993). While we agree that changes in attitudes across extended periods of time (years) could be measured using the ATS, the way that the measure has been used has been to look at attitude changes within a single testing session, or in response to changing the labels in the measure. While changes might be observed when using the measure in this way, the visceral and extreme nature of attitudes toward this population means that it is likely that any observed differences are due either to demand characteristics (for changes within a single session) or are not reflective of broad attitudes to sexual offenders (for differences as a function of the label used). 
Another issue related to the use of the ATS in existing work is that of the scoring procedure. It is unclear in a number of studies as to whether Hogue's (1993) scoring procedure has been adequately followed. In one study (Johnson, Hughes, \& Ireland, 2007), the mean ATS score attributed to members of the public was almost equivalent to the scores attributable to sexual offenders in Hogue's (1993) original development paper. A result such as this is indicative of an error in not removing the constant of 36 and leads to inflated (more positive) scores for particular groups being published within the ATS literature (see also Radley, 2011; Sanghara \& Wilson, 2006). Further, Kleban and Jeglic (2012) reported success in relation to their psychoeducational interventions for attitudes toward sexual offenders. However, in relation to their scoring of the ATS as an outcome measure, they stated that "a lower total score was an indication of positive endorsement, or less negative attitudes" (p. 187), when in fact a lower total score is an indication of more negative attitudes. Errors in the scoring of the ATS lead to substantial problems in comparing scores across samples or studies, potentially leading to an inconsistent and contradictory body of work.

The CATSO scale. The CATSO (Church et al., 2008) is an 18-item self-report measure. It was developed as an alternative to other measures that, according to the authors, had either: (1) not been adequately validated, or (2) been developed based on measures designed to examine attitudes toward other (i.e., general offender) populations.

Like the ATS, items on the CATSO are composed as statements about sexual offenders (e.g., "Most sex offenders are unmarried men"). Respondents indicate their level of agreement with each statement using a six-point Likert scale, anchored from 1 ('Strongly Disagree') to 6 ('Strongly Agree'). Scores for each of the items are summed to provide a composite CATSO score that can range from 18-108 (higher scores indicate more negative views about sexual offenders). In a range of studies, the CATSO has demonstrated acceptable 
levels of internal consistency ( $\alpha>0.70$; Church et al., 2008; Conley, Hill, Church, Stoeckel, \& Allen, 2011; Jones, 2013; Malinen, Willis, \& Johnston, 2014; Shackley, Weiner, Day, \& Willis, 2014; Shelton, Stone, \& Winder, 2013).

Church et al.'s (2008) initial factor analyses of the CATSO data identified a four-factor structure underpinning the scale, with these being labeled 'Social Isolation', 'Capacity to Change', 'Dangerousness', and 'Deviancy'. Each of these factors (with the exception of 'Deviancy') demonstrated acceptable levels of internal consistency (all $\alpha$ 's $>0.70)$. A number of studies have sought to validate the CATSO with new factor analyses (e.g., Conley et al., 2011; Harper \& Hogue, 2015; Shackley et al., 2014; Shelton et al., 2013; Tewksbury \& Mustaine, 2013). However, none of these studies (with the exception of Tewksbury \& Mustaine, 2013) have replicated the same underlying factor structure as Church et al. (2008). Some studies have found the CATSO to be comprised of two factors (e.g., 'Social Isolation' and 'Capacity for Change'; Conley et al., 2011), while others have identified a different four factor structure than that reported in Church et al.'s (2008) original development paper (e.g., 'Social Tendencies', 'Treatment and Punishment', 'Crime Characteristics', and 'Sexual Behavior'; Shackley et al., 2014). Interpreting this latter structure, there is a case to be made that the CATSO actually examines knowledge-based attributions about sexual offenders (and thus is a measure of 'perceptions', rather than 'attitudes').

The lack of structural consistency within the CATSO has led to some authors calling for partial or complete overhauls of the measure (e.g., Conley et al., 2011; Shackley et al., 2014; Shelton et al., 2013). Harper and Hogue (2015) sought to reconceptualize the CATSO as an outcome measure of sentencing, stereotype, and risk-based judgments after conducting a face validity analysis of CATSO items, and adding additional items that mapped onto their observed themes within the CATSO. Using a sample of 400 British community members, they found that this broad three-factor structure (with factors related to sentencing 
preferences, risk assessment, and stereotype endorsement) was supported through a systematic process of principal components and confirmatory factor analyses. Their resultant 20-item Perceptions of Sex Offenders (PSO) scale was recommended as a successor to the CATSO, and arguably offers a more conceptually-sound approach to measuring such outcome-based evaluations of sexual offenders.

\section{Contributions of this Paper}

Given the various methodological shortcomings of the current tools used to measure attitudes toward sexual offenders, we present a revalidation of Hogue's (1993) ATS measure in this paper. Comparative to other scales in use in this area, such as the CATSO (Church et al., 2008), the ATS is a long scale (36 vs. 18 items). This makes it a more cumbersome measure and hinders its offline use due to the logistical and time constraints faced by many researchers - particularly those interested in professional attitudes in secure settings. Further, the ATS has been sparsely used with general public samples, and its underlying factor structure has not been comprehensively examined in the existing literature.

As such the original contribution of this paper is to produce a shorter, more useable, and theoretically-anchored version of the ATS. The underlying factor structure of the ATS is examined and confirmed using data from two large community samples in order to establish its conceptual fit with the ABC model of 'attitudes' outlined earlier in the paper. By using community samples at this stage, it is possible to examine the underlying factor structure of the ATS without the interference or added variance of professionals' clinical experience influencing the data. Following from this, the revised ATS model will be applied to data from the original Hogue (1993) development sample as a proxy for an analysis of test-retest reliability and scale validity. Normed data for both the original and revised forms of the ATS are provided throughout in relation to the community and professional groups that we have 
sampled, such as to facilitate future score comparisons across this area of literature. Finally, we demonstrate how the context in which the revised ATS measure does not change the total scores obtained using it but improves functionality through the addition of theoreticallyanchored subscales. This should provide confidence to researchers who wish to use this new measure in a range of professional and community settings. As such, we address issues around the conceptual and practical utility of the ATS by examining its factor structure and producing its length. We further address limitations related to the inconsistent use of the ATS by providing SPSS data files and scoring syntax to enable consistent scoring and interpretation of the measure in future studies.

\section{Study 1}

In a bid to develop a usable short-version of Hogue's (1993) ATS measure, we first sought to examine its underlying factor structure in a general public sample.

\section{Method}

Participants. The participants for Study 1 consisted of 188 participants $(62.8 \%$ female) recruited within the main shopping area of a small British city. There was an acceptable age split in the sample (under 35 years $n=91 ; 35$ years or older $n=97$ ), and 93.6\% of participants were born in the UK. These data were initially collected as part of two parallel studies examining the effect of perpetrator sex on perceptions of sexual crime (Ranger, 2011; Wilson, 2011). Responses to the demographic information and ATS measure (see below) were provided at the beginning of both studies, and subsequently combined for analysis in Study 1. All participants were approached randomly, with the intention being to capture a pseudo-representative sample of a community high street. Participants were informed of the nature of the study (i.e., that they would be asked about their views of sexual 
offenders) and that they could cease participation at any time. No participants were excluded or withdrew from the study.

Measures and procedure. Participants completed an anonymous demographic questionnaire (sex, age group, British born status) and the full 36-item form of Hogue's (1993) ATS measure as described earlier. In this sample the ATS had excellent internal consistency $(\alpha=.94)$. The scores on the ATS did not differ significantly between the two samples, $t(186)=-1.814, p=.071$, nor were they dependent on participant sex, $t(186)=.611$, $p=.542$. After completing these questionnaires, participants went on to provide specific questions related to the main intended outcomes of each specific study these data are drawn from. The results of these studies are described elsewhere and will not be referred to in this paper.

These studies were approved by the University of Lincoln, School of Psychology Research Ethics Committee, prior to the beginning of data collection and adhered to the ethical code of the British Psychological Society.

\section{Results and Discussion}

The sample of the 36 items of the ATS met the necessary assumptions for analysis, the Kaiser-Meyer-Olkin measure of sampling adequacy was calculated as 0.92, while Bartlett's test of sphericity was significant, $\chi^{2}(630)=3340.66, p<.001$. These outcomes indicate that our data were suitable for principal components analysis (PCA). Our sample size of 188 participants meets the minimum recommended threshold of five observations per scale item for factor analytic procedures (Costello \& Osborn, 2005).

In order to determine the number of statistically distinct ATS item clusters in our data, we ran a parallel in SPSS for Windows analysis using O'Connor's (2000) open-source syntax. 
This analysis revealed that three factors had raw data eigenvalues that exceeded the $95^{\text {th }}$ percentile estimated eigenvalue (the threshold for statistical distinctiveness) within this analysis. As such, we ran a PCA with the instruction to extract three factors using varimax rotation. Table 1 presents the rotated factor loadings for each of the 36 items across the three factors. To facilitate easier interpretation, those loadings over .50 are highlighted. The generated analysis accounted for $45.65 \%$ of the cumulative variance in ATS scores.

\section{[Insert Table 1 Around Here]}

An examination of the question content for those items loading over 0.5 (Field, 2005) was undertaken to determine the focus of each of the factors. Factor 1 ('Trust') comprised nine items related to issues of how much a sexual offender should be trusted (e.g., "You have to be constantly on your guard with sex offenders"). Factor 2 ('Intent') comprised eight items related to issues of sexual offenders' state of mind and interpersonal motivations (e.g., "Sex offenders are always trying to get something out of somebody”). Factor 3 ('Social Distance') comprised seven items related to issues of how detached participants felt from sexual offenders (e.g., "Sex offenders need affection and praise just like anybody else").

As the third factor had only seven questions that loaded at above Field's (2005) recommended threshold of 0.5 , it was decided to only retain the top seven loading items on each of the factors, such as to produce a short-form ATS with three factors of equal length. The revised 21-item short form of the ATS scale (the 'ATS-21') was highly reliable as a complete unidimensional scale $(\alpha=.91)$. Further, each factor also possessed very strong levels of internal consistency: Trust $\alpha=.83$; Intent $\alpha=.84$; Social Distance $\alpha=.79$. Items are scored in the same manner as the full 36-item ATS, with a functional item scoring range of 04 and scores being summed to compute outcomes. As such, the ATS-21 has a scoring range 
of 0-84, while each factor has a range of 0-28 (high scores indicate more positive attitudes). Each factor was highly correlated with both the complete ATS-21 measure ( $r$ s $>.85)$, and the other factors, though did not meet the threshold for collinearity (Table 2). This indicates that these three components of the ATS-21 conceptually represent distinct constructs that could be studied separately in future research studies.

We also ran this analysis with an oblique (promax) rotation. The solutions obtained from these analyses were very similar, with factors obtained using oblique and orthogonal rotation correlating at $r>.90$ for all factors across Studies 1-3. As such, we settled on the solution obtained from the orthogonal rotation, such as to maximize the uniqueness of each factor, and to obtain a solution with three equally-sized factors. This provides us with the clearest and simplest factor solution (Kline, 1994) The results of the obliquely-rotated PCA, and the associated factor correlations, are available in the Online Supplementary File accompanying this paper.

\section{[Insert Table 2 Around Here]}

\section{Study 2}

Having identified the above three-factor structure of the ATS-21, we sought to confirm this in a large and independent community sample. We conducted this analysis as our PCA sample was marginally above the minimum recommended sample size, meaning that confirmatory analysis can afford us a higher degree of confidence in the claims we made above.

\section{Method}

Participants. A sample of 383 Britons were recruited for broader cross-cultural study examining public perceptions of child sexual exploitation material (CSEM; commonly referred to as 'child pornography'). Of these, 335 fully completed the ATS measure $(57.3 \%$ 
female; $M_{\text {age }}=36.55$ years; $\left.S D=14.58\right) .83 \%$ of the sample $(n=278)$ completed the study after being recruited in person via direct approach in public places by a researcher based at a mid-sized British university online. Participants completed the survey independently using a laptop provided by one of the researchers. A minority of participants $(17 \% ; n=57)$ were recruited via community pages on a variety on social media websites using opportunistic and snowball sampling methods. The online sample had over-representations of men, $\chi^{2}=5.29, p$ $=.021$, and highly educated people, $\chi^{2}=7.88, p=.049$. Online participants were also significantly younger $(M=31.56, S D=14.41)$ as compared to offline participants $(M=$ $37.88, S D=14.99), t(380)=3.40, p=.001, d=0.43,95 \% \mathrm{CI}_{d}[0.18,0.67]$. In line with previous work on demographic difference in ATS scores as a function of education, online participants also held more positive attitudes toward sexual offenders $(M=69.63, S D=$ 22.40) than offline participants $(M=56.45, S D=21.24), t(333)=4.23, p<.001, d=0.62$, $95 \% \mathrm{CI}_{d}[0.33,0.90]$. While these differences are present, our aim in Study 2 was not to compare these groups, but rather to use their data to confirm the factor structure of the ATS21. As such, we do not consider these differences to be problematic, especially as they are consistent with observed trends in the ATS literature (Harper et al., 2017).

Materials and procedure. As in Study 1, participants were recruited as part of a broader set of studies and completed a comprehensive demographic questionnaire and the ATS measure (full 36-item form; Hogue, 1993) before moving on to study-specific measures. These broader studies were focused around perceptions of CSEM offending, and the results of these investigations are reported elsewhere (e.g., Hitikasch, Merdian, \& Hogue, 2017) and will not be discussed in this paper. The ATS demonstrated excellent internal consistency ( $\alpha=$ .94). As per Study 1, this study was approved by the University of Lincoln, School of 
Psychology Research Ethics Committee, prior to data collection and adhered to British Psychological Society ethical guidelines.

\section{Results and Discussion}

We used IBM Amos for SPSS (version 24) to run a confirmatory factor analysis (CFA) on the ATS-21 with the three-factor structure identified in Study 1 as the default model. The model diagram is presented in Figure 1.

\section{[Insert Figure 1 Around Here]}

As indicated in Figure 1, each item loaded well onto its proposed ATS-21 factor, and no items were covaried with other factors. We covaried each ATS-21 factor with the others owing to the correlations between them identified in Study 1 (Table 2). This model demonstrated acceptable with our data, particularly in light of the large sample size: comparative fit index $(\mathrm{CFI})=.84$; root square mean error of approximation $(\mathrm{RMSEA})=.08$.

With this CFA, we were able to confirm the three-factor structure of the ATS-21 scale that was reported in Study 1. This structure adheres well to the ABC model of attitudes in the introduction to this paper. That is, the extent to which an individual trusts sexual offenders (Factor 1) is a reflection of some affective attitude toward this group, as exemplified through the items proposing such things as "Sex offenders are immoral". In turn, judgements of sexual offenders' intent (Factor 2) corresponds to an ascription of their cognitive states of mind, as reflected in the item suggesting "Sex offenders are always trying to get something out of somebody". Finally, attitudes reflecting a desire for social distance (Factor 3) are, by definition, a behavioral manifestation of viewpoints about this group, as depicted by 
(dis)agreement with statements such as "If sex offenders do well in prison/hospital, they should be let out on parole".

As such, the ATS-21 serves as an appropriate alternative to the initial ATS measure (Hogue, 1993), but has the added advantages of being shorter (and thus more user-friendly), and theoretically stronger with regard to a coherent model of attitudes in the broader sense.

\section{Study 3}

The analyses in Studies 1 and 2 identified and confirmed a three-factor structure underpinning the revised ATS-21 measure using general community samples. With the full form of the ATS also being used with professional samples, we next sought to re-confirm this factor structure using a re-analysis of Hogue's (1993) original ATS development sample to establish whether this structure fit the initial data collected from sexual offenders and professionals working with them. We also set out to establish the relationship between scores on the initial full form ATS and the new ATS-21. Establishing this relationship is an important contribution to the literature, in that it allows for the direct comparison of scores on the ATS-21 with findings in the previous literature using 36-item version of the ATS.

\section{Method}

Participants. We used the sample and data from Hogue (1993) in this study. A sample of 170 individuals $\left(80 \%\right.$ male; $M_{\text {age }}=30.08$ years, $\left.S D=9.36\right)$ were recruited from a variety of locations in the British criminal justice system (e.g., prisons, probation, and police offices). Within this sample, there were subsamples of police officers $(n=33)$, prison officers both with $(n=50)$ and without $(n=21)$ responsibility for treatment, probation officers $(n=11)$, forensic psychologists $(n=21)$, and sexual offenders $(n=28)$. Six participants did not provide this grouping information. The motivation for including these groups was to examine 
whether working closely with (or being) sexual offenders improved attitudes toward this population. All participants were invited to take part in a study examining attitudes toward prisoners and sex offenders and were guaranteed anonymity in order to decrease motivations for socially desirable responding.

Materials and procedure. Participants were invited to participate in a variety of settings by direct approach by Hogue for the original Hogue (1993) data collection period. Example locations where participants were sample from include staff offices, at the beginning of professional training courses, and prison cells. Study booklets were distributed to those expressing an interest in taking part. These booklets included a demographic questionnaire asking about participant sex, age, and (for professional groups) job roles and years of experience. Next came the ATP measure (Melvin et al., 1985), followed by the ATS in its original 36-item form (Hogue, 1993). This study was undertaken as part a HM Prison Service evaluation (now Her Majesty's Prison \& Probation Service; HMPPS) and was approved by the national HMPS ethical review process in place at that time.

\section{Results and Discussion}

To begin, we conducted an equivalent CFA to that reported in Study 2 on the original ATS development data. The three-factor structure ('Trust', 'Intent', and 'Social Distance') was set as the default model. Item loadings and factor covariances are displayed in Figure 2.

[Insert Figure 2 Around Here]

As in Study 2, this three-factor structure of the ATS-21 demonstrated an acceptable fit to the initial ATS development data: $\mathrm{CFI}=.84, \mathrm{RMSEA}=.08$. Of note, these fit statistics are 
identical to those reported in Study 2. As such, we are confident that this factor structure is consistent across different samples (professional and community) and timepoints (new data was found to fit the same model as data collected for Hogue's (1993) initial development paper. This finding offers substantial weight to Harper and Hogue's (2015) argument that the ATS (and, by extension, the ATS-21) is a conceptually and empirically stronger assessment of attitudes toward sexual offenders than other measures wherein the factor structure has failed to replicate across multiple samples.

We next examined the relationships between scores on the full 36-item ATS and the ATS-21 within Hogue's (1993) development sample. We found a strong and statistically significant correlation between both forms of the ATS when looking at the whole sample, $r(168)=.98, p<.001$. We further examined this relationship within each subgroup of participants (where a group was indicated; $n=164$ ). This strong positive relationship was present in each subgroup. Given that one of Hogue's (1993) key findings was a significant stepwise difference in ATS scores between these groups, we provide mean ATS and ATS-21 scores alongside these correlation statistics in Table 3.

\section{[Insert Table 3 Around Here]}

\section{Study 4}

In light of attitudes toward sexual offenders being a politically-charged topic of investigation, there are concerns around the completion of explicit (self-report) measures with regard to social desirability (Harper et al., 2017). Further, the ATS are used in a variety of contexts. That is, researchers examining public attitudes typically make use of large-scale online surveys (e.g., Harper \& Bartels, 2018; Harper \& Hogue, 2017; Malinen et al., 2014; Shackley 
et al., 2014), while professional attitudes require more in-person testing due to resource constraints and equipment restrictions in secure settings (e.g., Blagden et al., 2016).

In Study 4, we sought to address these issues in a small exploratory study involving a convenience sample recruited on the campus of a small British university. Data was collected as part completion of a student research project (Stirland, 2016). That is, we examine the relationship between the ATS-21 and social desirability biases. We also test whether we would obtain different scores over two time points in different data collection contexts (online vs. in-person).

\section{Method}

Participants. We recruited a sample of 59 participants from a mid-sized university in the UK $\left(84.7 \%\right.$ female; $M_{\text {age }}=26.47$ years, $\left.S D=11.16\right)$. These participants represent a combination of students $(71.2 \%)$ and staff/members of the public $(28.8 \%)$ frequenting public areas of the campus. All participants were invited to take part in a study examining attitudes toward sexual offenders but were naïve to the specific aims of the study at the time of data collection.

Measures and procedure. Participants were invited to take part in a number of ways, including direct approach on campus, through a departmental undergraduate research participation scheme and via social media driven invitations disseminated by an undergraduate student. There were three conditions in this study, designed to examine whether responses to the ATS-21 changed as a function of the context in which it was completed. In all conditions, the survey was completed twice, with a period of two weeks between each sitting. 
In Condition 1, the survey was completed in person (and in the presence of a researcher) at both time points $(n=20)$. In Condition 2 , the survey was completed online at both time points $(n=19)$. In Condition 3, the survey was completed in person (and in the presence of a researcher) at the first time point, but online (and independently) at the second time point $(n=20)$. At the end of the second survey, participants received a comprehensive debrief about the study.

All data collection (both online and in-person) was conducted using a survey run using the Qualtrics online survey system. This survey contained a demographic questionnaire (participant sex, age), followed by the ATS-21 $(\alpha=.94)$, Harper \& Hogue's (2015) PSO measure $(\alpha=.90)$, and Reynolds' (1982) Social Desirability Scale (SDS; $\alpha=.85$ ). The SDS is a 13-item measure representing a shortened version of the much-used Marlow-Crowne measure of social desirability (Crowne \& Marlowe, 1960), and asks participants to rate whether they engage in specific behaviors (e.g., "I am always courteous, even to people who are disagreeable") using a binary true/false response. This procedure was approved by the University of Lincoln, School of Psychology Research Ethics Committee, prior to data collection and adhered to British Psychological Society ethical codes of conduct.

\section{Results and Discussion}

We started by testing whether there was a significant difference in ATS-21 scores at baseline between those who completed the survey in the presence of a researcher $(n=40)$ or independently online $(n=19)$. We found no significant difference between these scores, $t(57)$ $=1.09, p=.281, d=0.30,95 \% \mathrm{CI} d[-0.25,0.85]$, nor did scores differ between the conditions in relation to any of the individual ATS-21 factors; 'Trust': $t(57)=.80, p=.428, d$ $=0.22,95 \%$ CI $d[-0.33,0.77] ;$ 'Intent': $t(57)=.75, p=.457, d=0.21,95 \%$ CI $d[-0.34$, 0.76]; 'Social Distance': $t(57)=1.62, p=.110, d=0.45,95 \%$ CI $d[-0.10,1.00]$. 
While our sample size was small for this analysis, we did have around the minimum recommendation of 20 participants per cell (Simmons, Nelson, \& Simonsohn, 2011). Nonetheless, we would caution against using arbitrary significance values when interpreting these results. When examining the effect sizes of these differences (Cohen's $d$ ) we can see that there was a small-to-moderate difference in total ATS-21, 'Trust', and 'Intent' scores. However, the difference between the conditions in relation to desired 'Social Distance' was moderate-to-large, and indicated that those who completed the ATS-21 independently expressed more negative attitudes in this domain (a desire for more social distance) than those who completed the scale in the presence of a researcher. However, the $95 \%$ confidence intervals for each of these tests are wide and suggest no significant effects - possibly related to low statistical power in the analyses. These results should alleviate some fears about obtaining differences as a function of varying data collection contexts. However, broader testing to confirm these preliminary observations should be undertaken to validate these claims. The data from these baseline tests (and scores on all scales at both time points) are presented in Table 4.

[Insert Table 4 Around Here]

We next sought to establish the test-retest reliability of the ATS-21 and its factors in each of our conditions. Over a period of two weeks, we observed that these scores were highly correlated in all conditions, indicating excellent levels of temporal stability for the ATS-21 (this was also the case for the PSO and SDS measures; see Table 5).

[Insert Table 5 Around Here] 
We finally offer some preliminary evidence of the construct validity of the ATS-21 by examining its relationship with the PSO, which itself has its genesis in the Church et al.'s (2008) CATSO questionnaire, which purports to measure attitudes toward sexual offenders. As demonstrated in Table 6, the ATS-21 correlates at a moderate-to-high level with the PSO, with associations being higher for Factors 2 (Intent) and 3 (Social Distance). This is supportive of earlier claims made by Harper and Hogue (2015), who suggest that the CATSO (and, by extension, the PSO) measures stereotypical perceptions of sexual offenders (a cognitive issue related to the attributions we make about this group) and their behavioral implications. Thus, the ATS-21 seems to offer a fuller examination (in light of the ABC model described in the introduction to this paper) than other related measures.

Consistent with Study 1, the individual ATS-21 factors were more highly correlated with the full-scale score than with each other. However, between-factor correlations were higher in Study 4 than in Study 1, which may be a by-product of the smaller sample size. As observed by Schönbrodt and Perugini (2013), correlations seem to stabilize when $N=150$ 250. As such, the between-factor correlations reported in Study 1 may be more accurate than those reported in Study 4. Nonetheless, we would encourage researchers to consider and check for multicollinearity in their samples before deciding whether to use the ATS-21 in a unidimensional (if multicollinearity is present) or multidimensional (if multicollinearity assumptions are met) way.

Encouragingly, we found no evidence that ATS-21 scores (or scores on the PSO) were influenced by social desirability biases (all $r \mathrm{~s} \leq .05, p \mathrm{~s} \geq .662$ ). As noted by an anonymous reviewer, we did not include a fourth condition (online, followed by in person testing). While we have no reason to believe this particular sequence would yield different outcomes to those conditions that were tested, this is an interesting avenue for further exploration, particularly 
for researchers who pre-screen participants online before inviting them to in person testing sessions under laboratory conditions.

\section{General Discussion}

In this paper, we offer a unique contribution to the literature on attitudes toward sexual offenders by systematically presenting a revalidation of Hogue's (1993) ATS measure. The revised ATS-21 is comprised of three highly reliable factors ('Trust', Intent', and 'Social Distance'). While some researchers may still wish to use the ATS-21 in a unidimensional way to obtain global assessments of generalized attitudes for reasons of brevity or comparison between studies, we recommend using the three factor model as this represents a clearer and more theoretically valid approach to studying attitudes. The ATS-21 is also highly correlated with the 36-item full form ATS, its factor structure replicates in a range of samples, and we have provided preliminary evidence that it demonstrates excellent test-retest reliability, and the scores obtained from it are consistent in multiple testing contexts. As such, we recommend the use of the ATS-21 by researchers interested in attitudes toward sexual offenders in future studies.

\section{ATS-21 Scoring Procedure}

The short form ATS-21 is scored in the same manner as the original form of the ATS. That is, eleven items are reverse scored, and a constant of 21 (one for each ATS-21 item) is removed from the summed total of all item scores (for exact wording, see the Appendix to this article). Thus, the ATS-21 has a potential scoring range of 0-84, with high scores indicating positive attitudes toward sexual offenders. 
In order to facilitate consistent scoring of the ATS-21 across the field, a blank SPSS datasheet and scoring syntax for calculating full scale and factor scores, as well as reliability coefficients of the ATS-21, is freely available at https://osf.io/34hsx/.

\section{Theoretical and Practical Contribution}

Examining the factor structure of the ATS-21 provides the opportunity to examine whether this measure is a comprehensive measure of attitudes. We argue that the revised ATS-21 measure does provide such an examination, and measures attitudes in line with the tripartite ABC model that was outlined at the beginning of this paper (Breckler, 1984). The 'Trust' factor represents affect-based judgements about sexual offenders (e.g., "I would like associating with some sex offenders"), the 'Intent' factor examines cognitive, stereotyperelated, evaluations of sexual offenders (e.g., "Sex offenders only think about themselves"; reverse-scored), and the 'Social Distance' factor acts as a behavioral measure of views about sexual offenders (e.g., "If sex offenders do well in prison/hospital, they should be let out on parole").

This conceptual clarity and theoretical validity is the key difference between the revised ATS-21 and other scales within this area of research. For example, the CATSO (Church et al., 2008) is predominantly comprised of items examining cognitive evaluations of sexual offenders, and as such cannot be theoretically advocated as a comprehensive attitudinal measure, while the PSO (Harper \& Hogue, 2015) is, by design, an outcome measure looking at cognitive and behavioral manifestations of attitudes.

We initially highlighted two key methodological issues pertaining to the use of the original form of the ATS. We have contributed to the elimination of scoring errors by freely offering an SPSS-compatible datasheet and scoring syntax for the new ATS-21. The other limitation - that the ATS (or adapted versions of the ATS) has been commonly used as an 
outcome variable (Gakhal \& Brown, 2011; Harper, 2012; Kleban \& Jeglic, 2012) - requires further elaboration. Recent developments in relation to a reimagining of the CATSO measure has led to the potential to use such validated measures in a complementary way and avoid this conceptual misuse of the ATS. Although Church et al. (2008) conceptualized the ATS and CATSO measures as being in competition with each other, Harper \& Hogue (2015) drew upon criticisms of the validity and reliability of the CATSO to rethink its use as an outcome measure of views about sexual offender sentencing, rates of stereotype endorsement, and risk perception. With the resultant PSO scale now being available, we suggest that there is potential for a consistent research procedure to emerge in this area of scholarship.

When examining the effects of experimental stimuli (e.g., differentially-framed mock media presentations about sexual offenders, or vignettes about specific 'types' of sexual offenders) on judgments of sexual offenders, for instance, these manipulations could be preceded by the ATS-21 (along with other relevant baseline measures as deemed appropriate by researchers), and then followed by the PSO (along with other relevant study-specific outcomes). By following this procedure, it is possible to acquire research participants' baseline attitudes toward sexual offenders before priming them with an experimental stimulus. This temporally-based design is important, as researchers have previously found differences in data when asking participants about 'sexual offenders' (in a general sense) than when asking participants to respond to specific cases (e.g., Harper \& Bartels, 2018; Salerno et al., 2010). After an experimental manipulation, we then suggest the administration of the PSO as a measure of the cognitive and behavioral implications of the intervention or variable being studied. It would be important to include ATS-21 scores as a covariate in any analyses, such as to be confident that differences in PSO scores were due to the manipulation, rather than variances in baseline attitudes (Harper, Bartels, \& Hogue, 2018). Such a systematic and structured approach to research offers scholars an opportunity to unify this important, vibrant, 
but seemingly disparate field, in addition to being able to accurately, validly, and confidently assess the implications of a range of experimental manipulations.

\section{Limitations}

As observed in the specific sections above, Studies 3 and 4 possess relatively small subsample sizes for some groups. This is likely to limit the extent to which one can infer about these specific group norms and certainty about the stability of the measure. This is particularly the case for Study 4, where the results are used to make preliminary inferences about the contextual stability of the ATS-21. While we are confident in our conclusions, we would encourage independent pre-registered replications of these findings in order to provide greater confidence about their veracity. Similarly, in Study 3 we used data from Hogue's (1993) ATS development sample. This sample has inherent limitations owing to small subgroup sizes. Larger-scale replications of this work is also encouraged in order to produce more reliable estimates for normed group estimates.

We also acknowledge that the three-factor solution of the ATS-21 only explained around $45 \%$ of the variance in ATS scores (Study 1). While this number is not negligible, it does leave over half of the variance unexplained. Candidates for additional variables which might explain additional variance in attitudes toward sexual offenders include demographic factors (e.g., parenthood, educational background, politics; for a review of these issues see Harper et al., 2017), or psychological variables related to personality or moral values (Harper \& Harris, 2017). We recommend the inclusion of a range of these potentially relevant variables in subsequent work seeking to understand the psychological underpinnings of attitudes toward this population.

\section{Concluding Remarks}


We have presented a revised short form of the ATS measure of attitudes toward sexual offenders (Hogue, 1993). The ATS-21 is comprised of three underlying factors (labelled 'Trust', 'Intent', and 'Social Distance'), each of which are theoretically linked to the tripartite ABC model of attitudes (Breckler, 1984). Further, we have provided normed data in relation to the ATS-21, both in relation to several community and professional samples, against which researchers are able to compare data from their own studies. Finally, we outlined a potential paradigm for research into attitudes toward sexual offenders, making use of both this revised ATS-21 measure (at baseline), and Harper and Hogue's (2015) PSO (as an outcome). By adopting such as approach, and making use of available scoring aids, scholars in this field may be able to come together under a unified approach to research. Attitudes toward sexual offenders have substantial implications for decision-making in a range of contexts, and we hope that future research will adopt such rigorous a systematic paradigm in order to progress this field of study. 


\section{References}

Bastian, B., Denson, T. F., \& Haslam, N. (2013). The roles of dehumanization and moral outrage in retributive justice. PlosONE, 8, e61842. doi: 10.1371/journal.pone.0061842.

Blagden, N., Winder, B., \& Hames, C. (2016). "The treat us like human beings" Experiencing a therapeutic sex offenders prison: Impact on prisoners and staff and implications for treatment. International Journal of Offender Therapy and Comparative Criminology, 60, 371-396. doi: 10.1177/0306624X14553227.

Breckler, S., J. (1984). Empirical validation of affect, behavior, and cognition as distinct components of attitude. Journal of Personality and Social Psychology, 47, 1191-1205. doi: 10.1037/0022-3514.47.6.1191.

Brown, S. (1999). Public attitudes toward the treatment of sex offenders. Legal and Criminological Psychology, 4, 239-252. doi: 10.1348/135532599167879.

Church, W. T., Wakeman, E. E., Miller, S. L., Clements, C. B., \& Sun, F. (2008). The community attitudes toward sex offenders scale: The development of a psychometric assessment instrument. Research on Social Work Practice, 18, 251-259. doi: 10.1177/1049731507310193.

Conley, T., Hill, K., Church, W. T., Stoeckel, E., \& Allen, H. (2011). Assessing probation and community corrections workers' attitudes toward sex offenders using the attitudes toward sex offenders (CATSO) scale in a rural State. Sexual Addiction \& Compulsivity, 18, 75-85. doi: 10.1080/10720162.2011.582775.

Cook, L., \& Hogue, T. (2013). Not-In-My Backyard! A comparison of NIMBY responses to wind turbines and sex offender rehabilitation facilities. Paper presented at the BPS Division of Forensic Psychology Annual Conference. Belfast, Northern Ireland. 
Costello, A. B., \& Osborne, J. W. (2005). Best practices in exploratory factor analysis: For recommendations for getting the most from your analysis. Practical Assessment, Research \& Evaluation, 10, 1-9.

Craig, L. A. (2005). The impact of training on attitudes towards sex offenders. Journal of Sexual Aggression, 11, 197-207. doi: 10.1080/13552600500172103.

Crowne, D. P., \& Marlowe, D. (1960). A new scale of social desirability independent of psychopathology. Journal of Consulting Psychology, 24, 349-354. doi: 10.1037/h0047358.

Field, A. (2005). Discovering statistics using SPSS (2nd edition). London: Sage.

Gakhal, B. K., \& Brown, S. J. (2011). A comparison of the general public's, forensic professionals' and students' attitudes towards female sex offenders. Journal of Sexual Aggression, 17, 105-116. doi: 10.1080/13552600.2010.540678.

Galeste, M., Fradella, H., \& Vogel, B. (2012). Sex offender myths in print media: Separating fact from fiction in U.S. newspapers. Western Criminology Review, 13, 4-24.

Harper, C. A. (2012). In pursuit of the beast: Undergraduate attitudes towards sex offenders and implications for society, rehabilitation, and British psychology education. Internet Journal of Criminology. Retrieved from http://www.internetjournalofcriminology.com/Harper_In_Pursuit_of_the_Beast_IJC_July _2012.pdf.

Harper, C. A., \& Bartels, R. M. (2018). Implicit theories and offender representativeness in judgments of sexual crime. Sexual Abuse, 30, 276-295. doi: 10.1177/1079063216658019.

Harper, C. A., Bartels, R. M., \& Hogue, T. E. (2016). Reducing stigma and punitive attitudes toward pedophiles through narrative humanization. Sexual Abuse, 30, 533-555. doi: $10.1177 / 1079063216681561$. 
Harper, C. A., \& Harris, A. J. (2017). Applying moral foundations theory to understanding public views of sexual offending. Journal of Sexual Aggression, 23, 111-123. doi: $10.1080 / 13552600.2016 .1217086$.

Harper, C. A., \& Hogue, T. E. (2015). Measuring public perceptions of sex offenders: reimagining the Community Attitudes Toward Sex Offenders scale (CATSO). Psychology, Crime \& Law, 21, 452-470. doi: 10.1080/1068316X.2014.989170.

Harper, C. A., \& Hogue, T. E. (2017). Press coverage as a heuristic guide for social decisionmaking about sexual offenders. Psychology, Crime \& Law, 23, 118-134. doi: 10.1080/1068316X.2016.1227816.

Harper, C. A., Hogue, T. E., \& Bartels, R. M. (2017). Attitudes towards sexual offenders: What do we know, and why are they important? Aggression and Violent Behavior, 34, 201-213. doi: 10.1016/j.avb.2017.01.011.

Harris, A. J., \& Socia, K. M. (2016). What's in a name? Evaluating the effects of the "sex offender" label on public beliefs and opinions. Sexual Abuse, 28, 660-678. doi: $10.1177 / 1079063214564391$.

Higgins, C., \& Ireland, C. A. (2009). Attitudes towards male and female sex offenders: a comparison of forensic staff, prison officers and the general public in Northern Ireland. British Journal of Forensic Practice, 11, 14-19. doi: 10.1108/14636646200900004.

Hitikasch, M., Merdian, H. L., \& Hogue, T. (2017) Perceptions of narrative child sexual exploitation material in a German community sample. Sexual Offender Treatment, 11, 113.Hogue, T. E. (1993). Attitudes towards prisoners and sex offenders. In N. C. Clark and G. Stephenson (Eds.), DCLP occasional papers: Sexual offenders (pp. 27-32). Leicester, UK: British Psychological Society. 
Hogue, T. E., \& Peebles, J. (1997). The influence of remorse, intent and attitudes toward sex offenders on judgments of a rapist. Psychology, Crime \& Law, 3, 249-259. doi: 10.1080/10683169708410821.

Johnson, H., Hughes, J. G. \& Ireland, J. L. (2007). Attitudes towards sex offenders and the role of empathy, local of control and training: A comparison between a probationer police and general public sample. The Police Journal, 80, 28-54. doi:

10.1350/pojo.2007.80.1.28.

Jones, E. C. (2013). An examination of counseling professional/paraprofessionals attitudes toward adolescent sex offenders. SAGE Open, 2, 1-14. doi: 10.1177/2158244013501330.

Kjelsberg, E., \& Loos, L. H. (2008). Conciliation or condemnation? Prison employees' and young people's attitudes towards sexual offenders. International Journal of Forensic Mental Health, 7, 95-103. doi: 10.1080/14999013.2008.9914406.

Kleban, H., \& Jeglic, E. (2012). Dispelling the myths: Can psychoeducation change public attitudes towards sex offenders? Journal of Sexual Aggression, 18, 179-193. doi: $10.1080 / 13552600.2011 .552795$.

Klein, P. (1994). An easy guide to factor analysis. London: Routledge.

Lowe, G., Willis, G., \& Gibson, K. (2017). You do what? A qualitative investigation into the motivation to volunteer with circles of support and accountability. Sexual Abuse. Advance online publication. doi: 10.1177/1079063217729157.

Malinen, S., Willis, G. W., \& Johnston, L. (2014). Might informative media reporting of sexual offending influence community members' attitudes towards sex offenders? Psychology, Crime \& Law, 20, 535-552. doi: 10.1080/1068316X.2013.793770.

Melvin, K. B., Gramling, L. K., \& Gardner, W. M. (1985). A scale to measure attitudes towards prisoners. Criminal Justice and Behavior, 12, 241-252. doi: $10.1177 / 0093854885012002006$. 
O'Connor, B. P. (2000). SPSS and SAS programs for determining the number of components using parallel analysis and Velicer's MAP test. Behavior Research Methods, Instruments, \& Computers, 32, 396-402. doi: 10.3758/BF03200807.

Proeve, M. J., \& Howells, K. (2006). Effects of remorse and shame and criminal justice experience on judgements about a sex offender. Psychology, Crime \& Law, 12, 145-161. doi: 10.1080/10683160512331316271.

Radley, L. (2011). Attitudes toward sex offenders. Forensic Update, 66, 5-9.

Ranger, G. (2011). Public attitudes towards sex offenders and the community reintegration of a male and female sex offender. Unpublished dissertation. <institution masked for blinded review>.

Reynolds, W. M. (1982). Development of reliable and valid short forms of the MarloweCrowne social desirability scale. Journal of Clinical Psychology, 38, 119-125. doi: 10.1002/1097-4679(198201)38:1<119::AIDJCLP2270380118>3.0.CO;2-I.

Richards, K., \& McCartan, K. (2018). Public views about reintegrating child sex offenders via circles of support and accountability (COSA): A qualitative analysis. Deviant Behavior, 39, 400-416. doi: 10.1080/01639625.2017.1304800.

Salerno, J. M., Najdowski, C. J., Stevenson, M. C., Wiley, T. R., Bottoms, B. L., Vaca, R., \& Pimentel, P. S. (2010). Psychological mechanisms underlying support for juvenile sex offender registry laws: Prototypes, moral outrage, and perceived threat. Behavioral Sciences \& the Law, 28, 58-83. doi: 10.1002/bsl.921.

Sanghara, K. K., \& Wilson, J. C. (2006). Stereotypes and attitudes about child sexual abusers: a comparison of experienced and inexperienced professionals in sex offender treatment. Legal and Criminological Psychology, 11, 229-244. doi: 10.1348/135532505X68818. Schönbrodt, F. D., \& Perugini, M. (2013). At what sample size do correlations stabilize? Journal of Research in Personality, 47, 609-612. doi: 10.1016/j.jrp.2013.05.009. 
Shackley, M., Weiner, C., Day, A., \& Willis, G. W. (2014). Assessment of public attitudes towards sex offenders in an Australian population. Psychology, Crime \& Law, 20, 553572. doi: 10.1080/1068316X.2013.793772.

Shelton, L., Stone, J., \& Winder, B. (2013). Evaluating the factor structure and reliability of the community attitudes toward sex offenders (CATSO) scale. Journal of Criminal Psychology, 3, 115-126. doi: 10.1108/JCP-10-2012-0014.

Simmon, J. P., Nelson, L. D., \& Simonsohn, U. (2011). False-positive psychology: Undisclosed flexibility in data collection and analysis allows presenting anything as significant. Psychological Science, 22, 1359-1366. doi: 10.1177/0956797611417632.

Stirland, G. (2016). The influence of environment on reported attitudes and perceptions towards sex offenders. Unpublished dissertation. <institution masked for blinded review>.

Tewkesbury, R., \& Mustaine, E. E. (2013). Law-enforcement officials' views of sex offender registration and community notification. International Journal of Police Science \& Management, 15, 95-113. doi: 10.1350/ijps.2013.15.2.305.

Vess, J. (2009). Fear and loathing in public policy: Ethical issues in laws for sex offenders. Aggression and Violent Behavior, 14, 264-272. doi: 10.1177/1079063210382045.

Willis, G. M., Levenson, J. S., \& Ward, T. (2010). Desistance and attitudes towards sex offenders: Facilitation or hindrance? Journal of Family Violence, 25, 545-556. doi: 10.1007/s10896-010-9314-8.

Wilson, R. (2011). Public attitudes towards sex offenders: Determined by age and gender of the perpetrator. Unpublished dissertation. <institution masked for blinded review>. 


\section{Appendix: The ATS-21 Scale}

\section{Instructions}

Please respond to each of the following items using the scale provided. Please be as honest as possible in your responding. There are no right or wrong answers.

Response options

$0=$ strongly disagree

$1=$ disagree

$2=$ undecided

$3=$ agree

$4=$ strongly agree

\begin{tabular}{lll}
\hline No. & Item & Factor \\
\hline 1 & Sex offenders are different from other people (r) & Trust \\
2 & Most sex offenders are victims of circumstances and deserve help & Social Distance \\
3 & Sex offenders have feelings like the rest of us & Social Distance \\
4 & It is not wise to trust a sex offender too far (r) & Trust \\
5 & I think I would like a lot of sex offenders & Social Distance \\
6 & Give a sex offender an inch and they take a mile (r) & Intent \\
7 & Sex offenders need affection and praise just like anybody else & Social Distance \\
8 & Trying to rehabilitate sex offenders is a waste of time and money (r) & Intent \\
9 & Sex offenders are no better or worse than other people & Social Distance \\
10 & You have to be constantly on your guard with sex offenders (r) & Trust \\
11 & If you give a sex offender your respect, he'll give you the same & Social Distance \\
12 & Sex offenders only think about themselves (r) & Intent \\
13 & There are some sex offenders I would trust with my life & Trust \\
14 & Most sex offenders are too lazy to earn an honest living (r) & Intent \\
15 & I wouldn't mind living next door to a treated sex offender & Trust \\
16 & Sex offenders are just plain mean at heart (r) & Intent \\
17 & Sex offenders are always trying to get something out of somebody (r) & Intent \\
18 & Sex offenders are immoral (r) & Trust \\
19 & I would like associating with some sex offenders & Trust \\
20 & Sex offenders respect only brute force (r) & Intent \\
21 & If sex offenders do well in prison/hospital, they should be let out on & Social Distance \\
& parole & \\
\hline & & \\
& & \\
& &
\end{tabular}

\section{Notes}

- (r) indicates that the item is reverse-scored

- A blank SPSS datasheet and syntax for scoring the ATS-21 and establishing internal consistency is freely available from https://osf.io/34hsx/ 
Table 1. Rotated PCA item loadings of ATS scores onto three factors

\begin{tabular}{|c|c|c|c|c|}
\hline \multirow[b]{2}{*}{ No. } & \multirow[b]{2}{*}{ Item } & \multicolumn{3}{|c|}{ Component } \\
\hline & & 1 & 2 & 3 \\
\hline 6 & It is not wise to trust a sex offender too far & .706 & .163 & -.029 \\
\hline 16 & You have to be constantly on your guard with sex offenders & .642 & .241 & -.101 \\
\hline 23 & I wouldn't mind living next door to a treated sex offender & -.611 & -.262 & .372 \\
\hline 20 & There are some sex offenders I would trust with my life & -.593 & -.231 & .312 \\
\hline 1 & Sex offenders are different from other people & .552 & .085 & -.143 \\
\hline 29 & Sex offenders are immoral & .545 & .268 & -.271 \\
\hline 34 & I would like associating with some sex offenders & -.527 & -.157 & .445 \\
\hline 27 & I would never want one of my children dating a treated sex offender & .520 & -.054 & -.234 \\
\hline 26 & The values of most sex offenders are about the same as rest of us &.- .507 & -.098 & .497 \\
\hline 14 & You never know when a sex offender is telling the truth & .479 & .427 & -.095 \\
\hline 2 & Only a few sex offenders are really dangerous & -.474 & -.022 & .375 \\
\hline 33 & Some sex offenders are pretty nice people & -.448 & -.347 & .349 \\
\hline 3 & Sex offenders never change & .439 & .329 & -.137 \\
\hline 21 & Sex offenders will listen to reason & -.424 & -.312 & .379 \\
\hline 25 & Sex offenders are always trying to get something out of somebody & .318 & .709 & -.088 \\
\hline 24 & Sex offenders are just plain mean at heart & .249 & .701 & -.257 \\
\hline 22 & Most sex offenders are too lazy to earn an honest living & .008 & .668 & -.072 \\
\hline 35 & Sex offenders respect only brute force & .046 & .663 & -.158 \\
\hline 9 & Give a sex offender an inch and they take a mile & .463 & .576 & .032 \\
\hline 19 & Sex offenders only think about themselves & .347 & .568 & -.104 \\
\hline 13 & Trying to rehabilitate sex offenders is a waste of time and money & .232 & .517 & -.476 \\
\hline 31 & In general, sex offenders are basically bad people & .490 & .513 & -.392 \\
\hline 17 & In general, sex offenders think and act alike & .205 & .499 & -.154 \\
\hline 30 & Sex offenders should be under strict, harsh discipline & .468 & .493 & -.363 \\
\hline
\end{tabular}


28 Most sex offenders have the capacity for love

$-.227$

Most sex offenders are stupid

You should not expect too much from a sex offender

Sex offenders are no better or worse than other people

Most sex offenders are victims of circumstances and deserve help

11 Sex offenders need affection and praise just like anybody else

5 Sex offenders have feelings like the rest of us

18 If you give a sex offender your respect, he'll give you the same

7 I think I would like a lot of sex offenders

36 If sex offenders do well in prison/hospital, they should be let out on parole

32 Most sex offenders can be rehabilitated

8 Bad prison conditions just make sex offenders more bitter
$-.488$

.451

.350

.083

$-.224$

$-.355$

$-.400$

$-.238$

$-.028$

$-.446$

$-.472$

.014
.442

$-.111$

.012

.606

.600

.578

.573

.569

.525

.507

.490

.453

Note. Items loading higher than .50 onto a factor are highlighted in bold typeface. 
Table 2. Correlations between ATS-21 factors (Study 1)

\begin{tabular}{lc|ccc}
\hline & $\begin{array}{c}\text { ATS-21 } \\
\text { (Total) }\end{array}$ & $\begin{array}{c}\text { Factor 1 } \\
\text { (Trust) }\end{array}$ & $\begin{array}{c}\text { Factor 2 } \\
\text { (Intent) }\end{array}$ & $\begin{array}{c}\text { Factor 3 } \\
\text { (Social Distance) }\end{array}$ \\
\hline ATS-21 (total) & - & & & \\
ATS-21 Factor 1 (Trust) & .87 & - & - & \\
ATS-21 Factor 2 (Intent) & .86 & .61 & .59 & 12.82 \\
ATS-21 Factor 3 (Social Distance) & .86 & .63 & 15.83 & 4.89 \\
\hline$M$ & 36.81 & 8.16 & 5.22 & 0.79 \\
$S D$ & 13.14 & 5.18 & 0.84 & \\
\hline$\alpha$ & 0.91 & 0.83 & & 0.8 \\
\hline
\end{tabular}

Note. All correlations are significant at $p<.001$. 
Table 3. Normed data and relationships between ATS and ATS-21 scores in Hogue's (1993) development sample

\begin{tabular}{lccccccc}
\hline & $n$ & ATS Score & Total & Trust & Intent & $\begin{array}{c}\text { ATS-21 } \\
\text { Social } \\
\text { Distance }\end{array}$ & $\begin{array}{c}\text { ATS vs. ATS-21 } \\
\text { Correlation }\end{array}$ \\
\hline Whole sample & 170 & $80.09(19.84)$ & $46.65(12.03)$ & $12.22(5.27)$ & $19.28(3.79)$ & $15.15(4.31)$ & $r(168)=.98, p<.001$ \\
\hline Police officers & 33 & $62.61(16.47)$ & $35.58(10.23)$ & $7.85(4.08)$ & $16.67(3.75)$ & $11.06(3.76)$ & $r(31)=.98, p<.001$ \\
Prison officers (not treatment) & 21 & $71.48(17.35)$ & $41.38(10.10)$ & $9.71(4.28)$ & $18.67(3.46)$ & $13.00(3.91)$ & $r(19)=.97, p<.001$ \\
Prison officers (treatment) & 50 & $79.96(13.13)$ & $46.44(8.50)$ & $12.04(4.31)$ & $18.84(2.94)$ & $15.56(2.69)$ & $r(48)=.97, p<.001$ \\
Probation officers & 11 & $91.46(10.92)$ & $53.73(7.84)$ & $15.36(3.17)$ & $21.27(3.20)$ & $17.09(2.47)$ & $r(9)=.95, p<.001$ \\
Forensic psychologists & 21 & $90.38(12.25)$ & $51.81(8.16)$ & $14.10(3.33)$ & $21.14(3.12)$ & $16.57(3.40)$ & $r(19)=.96, p<.001$ \\
Sexual offenders & 28 & $99.14(20.42)$ & $57.00(12.64)$ & $16.89(5.93)$ & $21.32(4.30)$ & $18.79(4.35)$ & $r(26)=.98, p<.001$ \\
\hline
\end{tabular}

Note. Values represent mean scores in each scale with standard deviations in parentheses. 
Table 4. ATS-21, PSO, and social desirability scores, by time point and study condition (Study 4)

\begin{tabular}{|c|c|c|c|c|c|c|}
\hline & \multicolumn{2}{|c|}{ Condition 1 (In Person/In Person) } & \multicolumn{2}{|c|}{ Condition 2 (Online/Online) } & \multicolumn{2}{|c|}{ Condition 3 (In Person/Online) } \\
\hline & Time 1 & Time 2 & Time 1 & Time 2 & Time 1 & Time 2 \\
\hline ATS-21 & $47.55(14.81)$ & $46.45(15.04)$ & $43.40(10.93)$ & $44.25(11.64)$ & $41.37(14.63)$ & $42.63(15.73)$ \\
\hline Trust & $12.50(6.41)$ & $11.40(5.61)$ & $9.70(4.40)$ & $10.30(4.30)$ & $9.89(4.98)$ & $10.53(5.58)$ \\
\hline Intent & $18.55(5.76)$ & $18.50(6.29)$ & $17.95(3.97)$ & $17.90(4.27)$ & $17.16(5.90)$ & $17.37(6.25)$ \\
\hline Social Distance & $16.50(3.98)$ & $16.55(4.71)$ & $15.75(3.52)$ & $16.05(4.39)$ & $14.32(4.53)$ & $14.74(5.13)$ \\
\hline PSO & $58.10(8.98)$ & $55.60(9.01)$ & $56.80(9.64)$ & $56.53(7.27)$ & $58.11(9.60)$ & $59.95(8.53)$ \\
\hline SDS & $1.45(0.18)$ & $1.48(0.22)$ & $1.38(0.22)$ & $1.50(0.29)$ & $1.38(0.19)$ & $1.39(0.23)$ \\
\hline
\end{tabular}

Scale (Reynolds, 1982). 
Table 5. Correlations between ATS-21, PSO, and social desirability scores at both time points, by study condition (Study 4)

\begin{tabular}{lccr}
\hline & Condition 1 (In Person/In Person) & Condition 2 (Online/Online) & Condition 3 (In Person/Online) \\
\hline ATS-21 & $r(18)=.87, p<.001$ & $r(17)=.98, p<.001$ & $r(18)=.82, p<.001$ \\
Trust & $r(18)=.72, p<.001$ & $r(17)=.88, p<.001$ & $r(18)=.74, p<.001$ \\
Intent & $r(18)=.86, p<.001$ & $r(17)=.97, p<.001$ & $r(18)=.92, p<.001$ \\
Social Distance & $r(18)=.70, p<.001$ & $r(17)=.91, p<.001$ & $r(18)=.75, p<.001$ \\
PSO & $r(18)=.84, p<.001$ & $r(17)=.86, p<.001$ & $r(18)=.77, p<.001$ \\
SDS & $r(18)=.74, p<.001$ & $r(17)=.77, p<.001$ & $r(18)=.77, p<.001$ \\
\hline
\end{tabular}

Note. ATS-21 = revised 21-item ATS scale, PSO = Perceptions of Sex Offenders Scale (Harper \& Hogue, 2015); SDS = Social Desirability

Scale (Reynolds, 1982). Statistics represent the association in scores for each variable between time points one and two. 
Table 6. Baseline correlations between ATS-21 scores, PSO scores, and social desirability (Study 4)

\begin{tabular}{|c|c|c|c|c|c|c|}
\hline & \multicolumn{6}{|c|}{ Scale } \\
\hline & 1 & 2 & 3 & 4 & 5 & 6 \\
\hline 1. ATS-21 (Total Score) & - & & & & & \\
\hline 2. ATS-21 (Trust) & $.93 *$ & - & & & & \\
\hline 3. ATS-21 (Intent) & $.94 *$ & $.80 *$ & - & & & \\
\hline 4. ATS-21 (Social Distance) & $.93 *$ & $.79 *$ & $.82 *$ & - & & \\
\hline 5. PSO & $-.60 *$ & $-.42 *$ & $-.67 *$ & $-.59 *$ & - & \\
\hline 6. SDS & .05 & .05 & .05 & .04 & .04 & - \\
\hline
\end{tabular}

Note. ATS-21 = revised 21-item ATS scale, PSO = Perceptions of Sex Offenders Scale (Harper \& Hogue, 2015); SDS = Social Desirability Scale (Reynolds, 1982).

$* p<.001$ 


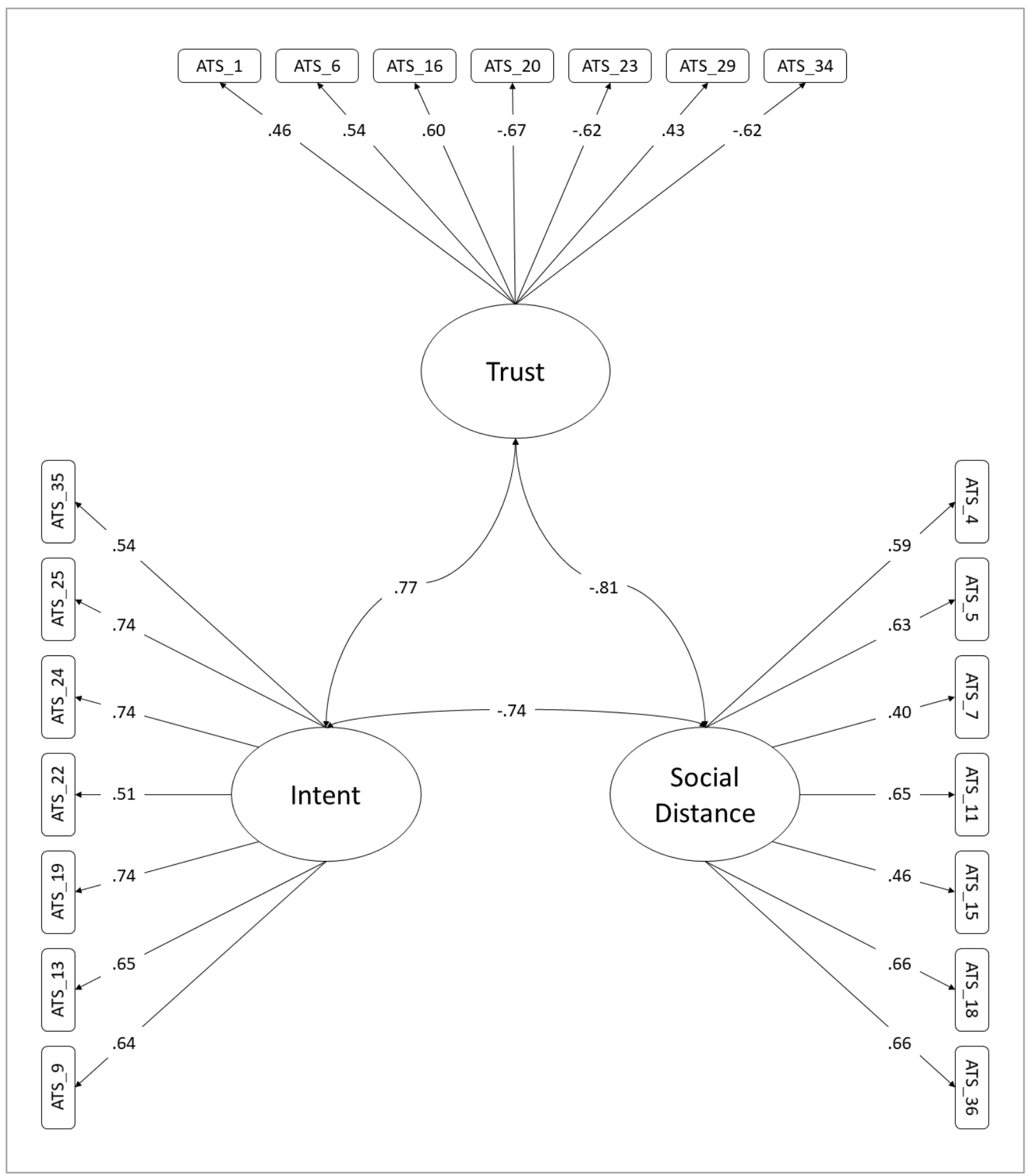

Figure 1. Confirmatory factor analysis of the ATS-21 (Study 2; $n=383$ ) 


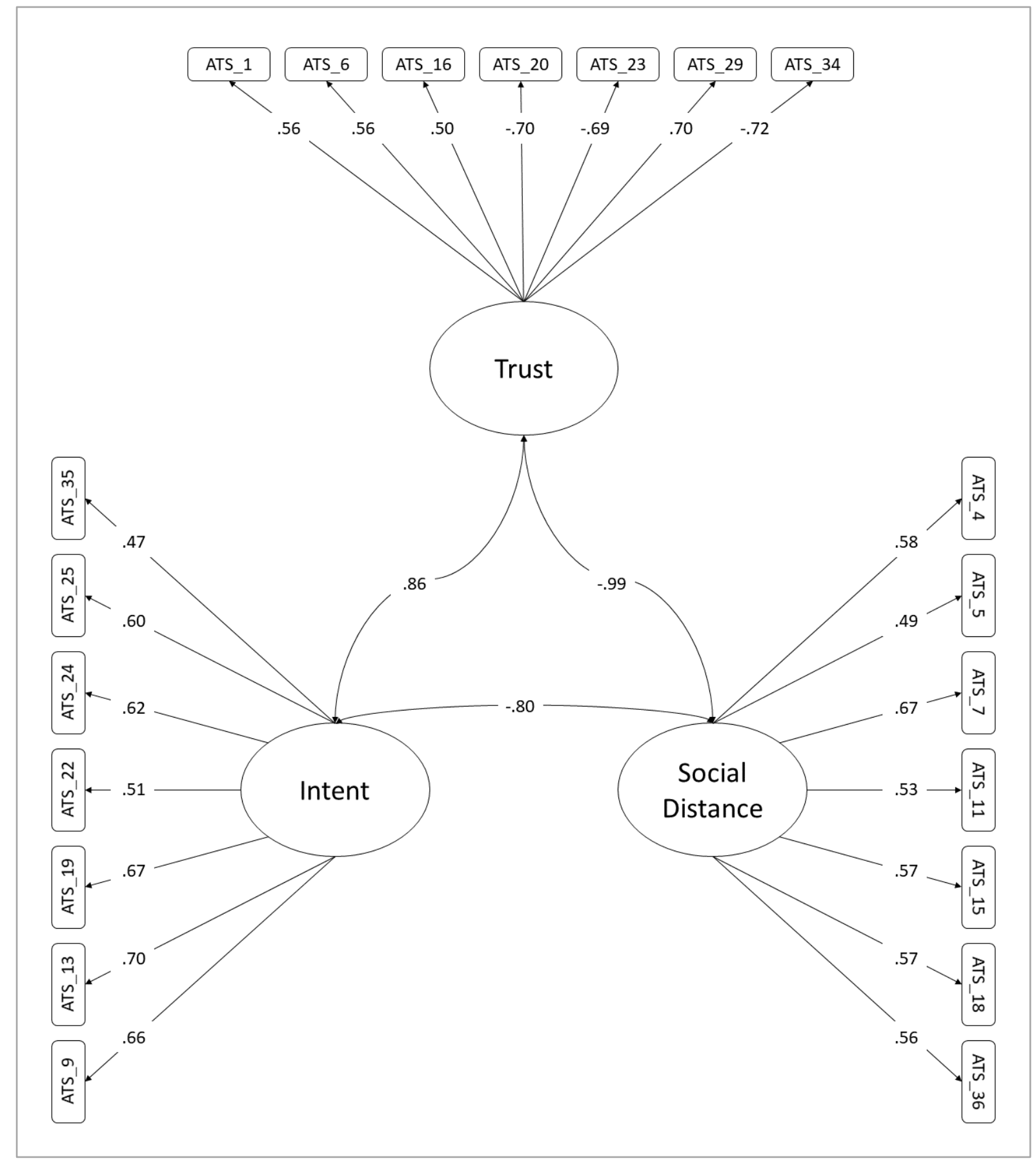

Figure 2. Confirmatory factor analysis of the ATS-21 based on Hogue's (1993) initial ATS development sample (Study 3; $n=170$ ) 